\title{
Surface-Generated Mesoscale Eddies Transport Deep-Sea Products from Hydrothermal Vents
}

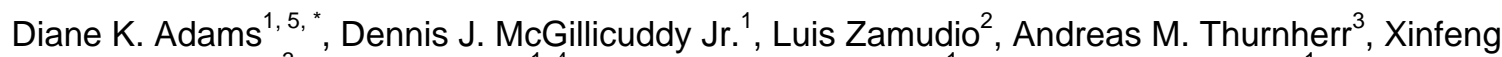 \\ Liang $^{3}$, Olivier Rouxel ${ }^{1,4}$, Christopher R. German $^{1}$, Lauren S. Mullineaux ${ }^{1}$
}

${ }^{1}$ Woods Hole Oceanographic Institution, Woods Hole, MA 02543, USA.

2 Center for Ocean-Atmospheric Prediction Studies, Florida State University, Tallahassee, FL 32306, USA

${ }^{3}$ Lamont- Doherty Earth Observatory, Palisades, NY 10964, USA.

${ }^{4}$ Université Européenne de Bretagne, Université de Brest, Institut Universaire Européen de la Mer (IUEM), UMR 6538, Institut Français de Recherche pour l'Exploitation de la Mer (IFREMER), BP 80 F29280 Plouzané, France.

${ }^{5}$ Current address: National Institutes of Health, National Institute of Dental and Craniofacial Research, Bethesda, MD 20892 USA

*Corresponding author : Diane K. Adams, email address : dadams@whoi.edu

\begin{abstract}
:
Atmospheric forcing, which is known to have a strong influence on surface ocean dynamics and production, is typically not considered in studies of the deep sea. Our observations and models demonstrate an unexpected influence of surface-generated mesoscale eddies in the transport of hydrothermal vent efflux and of vent larvae away from the northern East Pacific Rise. Transport by these deep-reaching eddies provides a mechanism for spreading the hydrothermal chemical and heat flux into the deep-ocean interior and for dispersing propagules hundreds of kilometers between isolated and ephemeral communities. Because the eddies interacting with the East Pacific Rise are formed seasonally and are sensitive to phenomena such as El Niño, they have the potential to introduce seasonal to interannual atmospheric variations into the deep sea.
\end{abstract}


Hydrothermal vents are hot spots for geological, geochemical, and biological activity that alter the global oceanic heat and chemical budgets $(1,2)$ and support unique chemosynthetic communities $(3,4)$. The disjunct distribution and transient nature of vents pose challenges for exporting vent-derived heat and chemicals into the global ocean and transporting propagules between distant vent fields. On short time scales, vent-derived products can remain close to the ridge axis. Chemical tracers can be used to locate hydrothermal vents (5); and larval supply to established vents is predominantly from local sources $(6,7)$. However, larvae and much of the seawater chemically altered at vents are eventually transported to distant locales. Hydrothermal seawater alterations contribute to the removal and addition of major chemical constituents (1), such as $\mathrm{Ca}$ and $\mathrm{Mg}$, as well as trace metals, such as $\mathrm{Fe}$ (8, 9) which may impact local and global biogeochemical cycling (10-12). Vent larvae must, at least episodically, undergo long distance dispersal to maintain observations of high gene flow $(13,14)$ and rapid colonization of disturbed and nascent vents ( 7 , 15). Ridge-trapped jets $(16,17)$ and hydrothermally-induced flows $(18)$ 
have the potential to transport material near the ridge. Yet, after decades of research at hydrothermal vents, the mechanisms by which heat, chemicals and larvae are transported throughout the global ocean and between distant vent fields remain poorly resolved.

To investigate mechanisms that transport vent fluids and larvae, we performed time-series observations of hydrodynamics and larval, chemical and mass fluxes in the $9^{\circ} 50^{\prime} \mathrm{N}$ area of the East Pacific Rise (EPR) (Fig. S1). Dramatic decreases in the larval supply of vent gastropods (Fig. 1A, Fig. S2, Fig. S3) and in mass flux associated with settling particles (Fig. 1B) were observed near the end of the time series and corresponded to a period of anomalous current velocities. Current velocities both on-axis (Fig. 1C, Fig. S4AB) and off-axis (Fig. S4C) reached speeds exceeding $15 \mathrm{~cm} \mathrm{~s}^{-1}$ during the anomaly, compared to the mean speed of $5.5 \mathrm{~cm} \mathrm{~s}^{-1}$ (at 170 meters above bottom). Using a permutation test, larval and mass fluxes were significantly lower than expected post-anomaly (during and after the velocity anomaly), $\mathrm{p}=0.0007$ and $\mathrm{p}=$ 0.008 , respectively. The biological and geochemical changes appear to have been driven by anomalous low-frequency currents (Fig. 1C), as the magnitude of high frequency motions was relatively stable during this time (Fig. S5).

The concurrent decreases (19) in larval supply and mass flux were most likely due to hydrodynamic transport away from the ridge rather than changes in source production. Both larval supply and mass flux are derived from independent pools built up over time, so changes in production would be observed as dampened or lagged changes in flux. Additionally, it is unlikely that mass flux sources and multiple species' reproduction changed concurrently. Hydrothermal vent gastropods typically exhibit continuous or quasi-continuous reproduction $(20,21)$ with precompetency periods. Therefore, we assume our samples come from a continuously produced larval pool that integrates reproductive output over time. 
In close proximity to vents that are distant from continents, mass flux is typically dominated by mineral particulates settling from the neutrally-buoyant plume supplied by hightemperature 'black-smoker' venting and the biogenic fluxes from adjacent chemosynthetic communities associated with low-temperature hydrothermal flow $(22,23)$ (see Supporting Online Material for detailed geochemical analysis of the mass flux). Consistent temperatures and chemistry of vent fluids in November 2004 and April 2005 (24, 25) indicate that changes in high-temperature and low-temperature hydrothermal flow cannot account for the decreases in mass flux at the end of the time series. Instead, we suggest that the hydrodynamic event displaced the resident water mass with its accumulated biogenic and mineral particulates resulting in decreased mass flux. Although a reduction in mineral particulates from hightemperature venting (e.g., Fe, Cu, and Zn, Fig. 1D, Table S1) was not observed during the hydrodynamic event, this does not necessarily imply that minerals and vent-altered seawater were not transported. Rapid production by vigorous venting, followed by prompt precipitation through quenching by cold, oxygenated bottom water, could replenish transported material over timescales that are short compared to our sampling interval, thus, masking any changes due to transport in the observed metal fluxes. Production of biogenic material from low-temperature vent communities would be markedly slower, such that displacement by the hydrodynamic event would be followed by delayed re-establishment of pre-anomaly fluxes. Thus, the observed variation in mass flux (Fig. 1B) and elemental fluxes (Fig. 1D, Table S1) was likely due to transport of vent-derived mineral and biogenic material followed by swift replenishment of minerals by high-temperature venting but slower replenishment of the biogenic material.

The rapid changes in direction and coherence between current meters (Fig. 1C, Fig. S4) separated by a few kilometers (Fig. S1) are consistent with the inference that the hydrodynamic 
event observed on the ridge was due to the passage of a mesoscale feature. Daily objective analysis of satellite-observed sea level anomalies revealed multiple eddies, including a 375 km diameter anticyclone originating in the Gulf of Tehuantepec in September 2004 that crossed the study site from February to March 2005 (Fig. 2, Movie S1), just prior to the anomalous bottom current velocities. Observed near-bottom current velocities were significantly negatively correlated with the inferred geostrophic flows associated with the eddy (Pearson correlation for the full five month record, $\left.\mathrm{r}_{u}=-0.20, \mathrm{p}_{u}=0.010 ; \mathrm{r}_{v}=-0.21, \mathrm{p}_{v}=0.0073\right)$. Given the potential for offset between the surface and deep flows and deformation and delay due to the ridge (26), we also allowed for a lag between the geostrophic (Fig. 2A) and near-bottom velocities (Fig. 1C) which improved the meridional correlation to $\mathrm{r}_{v}=-0.57, \mathrm{p}_{v}<0.0001$ with an 8 day lag. While we cannot rule out the possibility of a jet on the ridge flanks sweeping across the site (16), the significant correlations between the observed deep currents and the surface geostrophic currents suggest a relationship between the anomalous current velocities at depth and the passage of the anticyclonic eddy.

Simulations with the $1 / 12^{\circ}$ HYCOM ocean model (27) also showed intensified bottom current velocities associated with the passage of anticyclones at the end of the observational time series. As eddies formed off the coast of Central America and propagated westward, bottomcurrent velocities developed from weak, incoherent flows at the beginning of 2005 into coherent features with increased velocities by February (Fig. 3, Movie S2) and extending through the end of the time series. Simulated currents near the ridge and at the surface (Fig. S6) were significantly correlated over 90 days $\left(\mathrm{r}_{\mathrm{u}}=0.33, \mathrm{p}_{\mathrm{u}}=0.0015 ; \mathrm{r}_{\mathrm{v}}=-0.54, \mathrm{p}_{\mathrm{v}}<0.0001\right)$. Including a lag further improved the meridional correlation, $\mathrm{r}_{\mathrm{v}}=-0.62$, $\mathrm{p}_{\mathrm{v}}<0.0001$ (lagged 5 days). The strength of the cross-correlations and lag for the simulated currents are roughly consistent with 
those for our observations. Cross-correlations between near-bottom observed and simulated velocities from January through March 2005 were significant for the meridional component, $\mathrm{r}_{\mathrm{v}}=$ 0.51, $\mathrm{p}_{\mathrm{v}}<0.0001$ (Fig. S6), but not for the zonal component, $\mathrm{r}_{\mathrm{u}}=0.16, \mathrm{p}_{\mathrm{u}}=0.14$. Eddyassociated meridional flows may have been intensified along the north-south trending ridge, through topographically-induced, meridional eddy elongation (26) or topographically rectified flows (16); whereas the zonal flows may have diminished into the background flows during deformation by the ridge axis or been influenced by fine-scale topography not included in the model, resulting in lower correlations. Still, these comparisons suggest that eddy-induced current velocities at depth were present during the period of observed current velocity anomalies and associated decreases in mass and larval fluxes.

Our findings suggest eddy-driven impacts extend beyond the upper ocean and main thermocline (28) to include deep-sea benthic environments. Eddies at depth could play a major role in transporting hydrothermal vent-derived heat, chemicals, and biota in a relatively lowenergy environment. Transport could occur wherever mesoscale eddies interact with ridges, including the Mid-Atlantic Ridge, the Southwest Indian Ridge, and the East Scotia Ridge (29, 30), and the surrounding deep ocean. The strong observed decreases in larval and mass fluxes, together with a change in chemical compositions of the settling flux, during and after the current anomaly suggest that the passage of the eddy over the study site removed vent-altered seawater, larvae and associated biogenic matter. The observed local removal of larvae would be followed by inevitable loss to unsuitable habitat, but could also result in the delivery of those larvae to distant vent fields. Complex interactions within the simulated eddy field created an intensified deep northward current, that extended nearly eight degrees of latitude and interacted with the ridge for weeks (Fig. 3B, Movie S2), potentially providing a conduit for larval transport between 
vent fields. The deep-water expression of large and/or interacting eddies could thus disrupt more persistent pathways of larval supply such as local retention $(6,7)$ and transport by rectified mean flows $(16,17)$. However, the eddies provide a hydrodynamic mechanism to facilitate longdistance dispersal events such as that of Ctenopelta porifera observed at nascent vents over 300 km away from the nearest known source (7). A few long-distance dispersal events driven by these eddies could produce high gene flow amongst vent fields and, more broadly, in the deepsea in general.

There is the potential for multiple eddies to interact with the EPR each year (31-33). A second instance of a strong negative correlation $\left(\mathrm{r}_{\mathrm{u}}=-0.56, \mathrm{p}_{\mathrm{u}}<0.0001 ; \mathrm{r}_{\mathrm{v}}=-0.86, \mathrm{p}_{\mathrm{v}}<0.0001\right.$ with a 8 day lag) between a current anomaly observed on the ridge crest and inferred geostrophic velocities at the surface was detected from May through June 2007 (Fig. 4A,B), lending further support for eddy-induced current velocities at depth. In the eastern Pacific, an average of $3.5 \pm$ 1.2 (SD) Tehuantepec and $2.2 \pm 1.0$ (SD) Papagayo eddies (31) form each year during the late fall to early spring (31-33); a subset of these eddies, $2.2 \pm 0.9$ (SD) per year, cross the EPR during the winter and spring (Fig. 4C). In addition to the seasonal production of these eddies, Tehuantepec eddies strengthen and increase in frequency during El Niño years (31-33). Although the deep-sea, and hydrothermal vents, in particular, are often naïvely thought of as being isolated from the surface ocean and atmosphere, the interaction of surface-generated eddies with the deep sea offers a conduit for seasonality and longer-period atmospheric phenomena to influence the 'seasonless' deep sea. Thus, while hydrothermal sources of heat, chemical and larval fluxes do not exhibit seasonality, there is potential for long-distance transport and dispersal to have seasonal to interannual variability. 
References and Notes

1. J. M. Edmond et al., Earth and Planetary Science Letters 46, 759 (1979).

2. C. R. German, K. L. Von Damm, in Treatise of Geochemistry. (Elsevier-Pergamon, Oxford, 2004), vol. 6, pp. 181-222.

3. C. L. Van Dover, The Ecology of Deep-Sea Hydrothermal Vents (Princeton University Press, Princeton, New Jersey, 2000), pp. 424.

4. V. Tunnicliffe, A. G. McArthur, D. McHugh, Advances in Marine Biology 34, 353 (1998).

5. E. T. Baker, C. R. German, in Geophysical Monograph Series. (American Geophysical Union, Washington DC, 2004), vol. 148, pp. 245-266.

6. D. K. Adams, L. S. Mullineaux, Limnology and Oceanography 53, 1945 (2008).

7. L. S. Mullineaux, D. K. Adams, S. W. Mills, S. E. Beaulieu, Proceedings of the National Academy of Sciences of the United States of America 107, 7829 (2010).

8. $\quad$ S. A. Bennett et al., Earth and Planetary Science Letters 270, 157 (2008).

9. $\quad$ N.-C. Chu et al., Earth and Planetary Science Letters 245, 202 (2006).

10. B. M. Toner et al., Nature Geosciences 2, 197 (2009).

11. D. J. Mackey, J. E. O'Sullivan, R. J. Watson, Deep-Sea Research I 49, 877 (2002).

12. A. Tagliabue et al., Nature Geosciences 3, 252 (2010).

13. C. Craddock, W. R. Hoeh, R. A. Lutz, R. C. Vrijenhoek, Marine Biology 124, 137 (1995).

14. L. A. Hurtado, R. A. Lutz, R. C. Vrijenhoek, Molecular Ecology 13, 2603 (2004).

15. T. M. Shank et al., Deep-Sea Research II 45, 465 (1998). 
16. J. W. Lavelle, A. M. Thurnherr, J. R. Ledwell, D. J. McGillicuddy, L. S. Mullineaux, Journal of Geophysical Research 115, C12073, doi:10.1029/2010JC006426 (2010).

17. D. J. McGillicuddy, J. W. Lavelle, A. M. Thurnherr, V. K. Kosnyrev, L. S. Mullineaux, Deep-Sea Research I 57, 880 (2010).

18. R. E. Thomson et al., Nature 424, 545 (2003).

19. Close examination of the time-series presented in Fig. 1A indicates that the arrival of strongest eddy currents lags slightly behind the late-February initial drop in larval supply. Our data do not resolve whether this initial drop resulted from a stochastic biological change in larval supply or physical forcing by some other mechanism.

20. P. A. Tyler et al., Journal of Shellfish Research 27, 107 (2008).

21. P. A. Tyler, C. M. Young, Journal of the Marine Biological Association of the United Kingdom 2, 193 (1999).

22. C. R. German, S. Colley, A. Khripounoff, G. P. Klinkhammer, M. R. Palmer, Deep-Sea Research I 49, 1921 (2002).

23. A. Khripounoff et al., Deep-Sea Research I 55, 532 (2008).

24. T. S. Moore, T. M. Shank, D. B. Nuzzio, G. W. Luther, Deep-Sea Research II 56, 1616 (2009).

25. Constant temperatures and chemistry also suggest that changes in chemical cues cannot account for the observed changes in larval supply.

26. D. K. Adams, G. R. Flierl, Deep-Sea Research I 57, 1163 (2010).

27. (Materials and methods are available as supporting material on Science Online).

28. Eddies in Marine Science. A. R. Robinson, Ed. (Springer Verlag, Berlin, 1983), pp. 609.

29. L. L. Fu, D. B. Chelton, P.-Y. Le Traon, R. Morrow, Oceanography 23, 14 (2010). 
30. S. R. Jayne, J. Marotzke, Journal of Physical Oceanography 32, 3328 (2002).

31. D. M. Palacios, S. J. Bograd, Geophysical Research Letters 32, doi:10.1029/2005GL024324 (2005).

32. C. S. Willett, R. R. Leben, M. F. Lavin, Progress in Oceanography 69, 218 (2006).

33. L. Zamudio et al., Journal of Geophysical Research 111, C05001, doi:10.129/2005JC003182 (2006).

34. We are grateful for help at sea from S. Beaulieu, K. Buckman, D. Fornari, A. Fusaro, I. Garcia Berdeal, B. Govenar, B. Hogue, R. Jackson, S. Mills, C. Strasser, T. Shank, S. Worrilow, and to the Captains and crew, Alvin group, and Chief Scientists (M. Lilley and C. Vetriani) during Atlantis cruises AT11-20, 11-26, 15-12, and 15-26. Altimeter products were produced and distributed by AVISO (http://www.aviso.oceanobs.com/), as part of the Ssalto ground processing segment. V. Kosnyrev assisted in the analysis of altimetric data. Maureen Auro and Scot Birdwhistell assisted with geochemical analysis. The LADDER group provided input during numerous discussions. HYCOM simulations were performed as part of the projects Eddy Resolving Global Ocean Prediction Including Tides and Full Column Mixing for Numerical Ocean Models using challenge and non-challenge time from the Department of Defense High Performance Computing Modernization Office on Cray XT5 and IBM P6 computers at the Naval Oceanographic Office, Stennis Space Center. Support was provided by NSF grants OCE-0424953, OCE-0425361 and OCE-0647948, WHOI grants from DOEI and the Ocean Venture Fund, a NDSEG graduate fellowship to D.K.A., and the WHOI Jannasch Chair for Excellence in Oceanography to L.S.M. Larval fluxes, chemical fluxes, and current 
records from 2004-2005 have been deposited in the Marine Geoscience Data System:

RIDGE 2000 Data Portal. The authors declare no competing financial interests.

\section{Supporting Online Material}

www.sciencemag.org

Materials and Methods

Supporting Text

Figs. S1, S2, S3, S4, S5, S6

Table S1

SOM References

Movie S1, S2

Figure 1. Observations at the EPR ridge crest, East Wall. (A) Supply of vent gastropod larvae and (B) mass flux. Solid line indicates the mean flux. Dashed lines indicate the 95\% CI. (C) Current velocities recorded at 170 meters above bottom (2350 $\mathrm{m}$ depth). Note the strong currents and rapid changes in direction in March 2005. (D) Variability of Fe flux (bars) over the time series. Solid bars indicate samples analyzed as before (pre) the current anomaly. Open bars indicate samples during or after (post) the current anomaly.

Figure 2. Surface and deep expression of a mesoscale eddy. (A) Inferred geostrophic velocities at the surface and the associated time series of sea level anomalies (SLA) from 
November 2004 to May 2005. Two eddies pass during this time period: one in February - March during the period of bottom observations and a second from the end of April to May, just after the period of near-bottom observations. (B) Map of sea level anomaly on 21 February 2005 when an anticyclonic eddy was impacting the study site (white star). The track of the center of the eddy from birth on 10 September 2004 until exit from the study region on 01 May 2005, marked every four weeks (black circles) is superimposed on the map.

\section{Figure 3. HYCOM model simulation of anticyclone-induced current velocities at depth.}

(A) Simulated bottom currents at East Wall at $2350 \mathrm{~m}$ depth from January to April 2005. (B) Simulated sea surface height variations for 5 March 2005 (color shading) consistent with assimilated satellite observations of a Tehuantepec eddy over hydrothermal vent fields (white stars) including our study site (southern-most white star). The model also predicts intensified and coherent near-bottom currents (black arrows) associated with the eddy field. For clarity, every $4^{\text {th }}$ vector is plotted. The induced near-bottom currents are complex, but often include deep cyclones associated with anticyclones (identified by white arrows) consistent with the significant negative lagged correlations between the inferred geostrophic velocities and observed nearbottom velocities.

Figure 4. Multiple eddies interact with the EPR at depth. (A) Sea level anomalies (SLA) and inferred geostrophic currents show the passage of two anticyclonic eddies over the $9-10^{\circ} \mathrm{N}$ vent field from May through June 2007. (B) Coincident with the SLA, near-bottom current anomalies in the opposite direction were recorded on the EPR at $9^{\circ} 50.0^{\prime} \mathrm{N}, 104^{\circ} 17.4^{\prime} \mathrm{W}$ at $2430 \mathrm{~m}$ depth. Plots of SLA and inferred currents were lagged 8 days relative to the observed near-bottom 
current velocities. (C) Mesoscale eddies cross the EPR seasonally. Analysis of satellite altimetry from January 1993 to December 2009 indicates that an average of $2.2 \pm 0.9$ (SD) eddies crossed the EPR each year, predominantly during the first half of the year. 

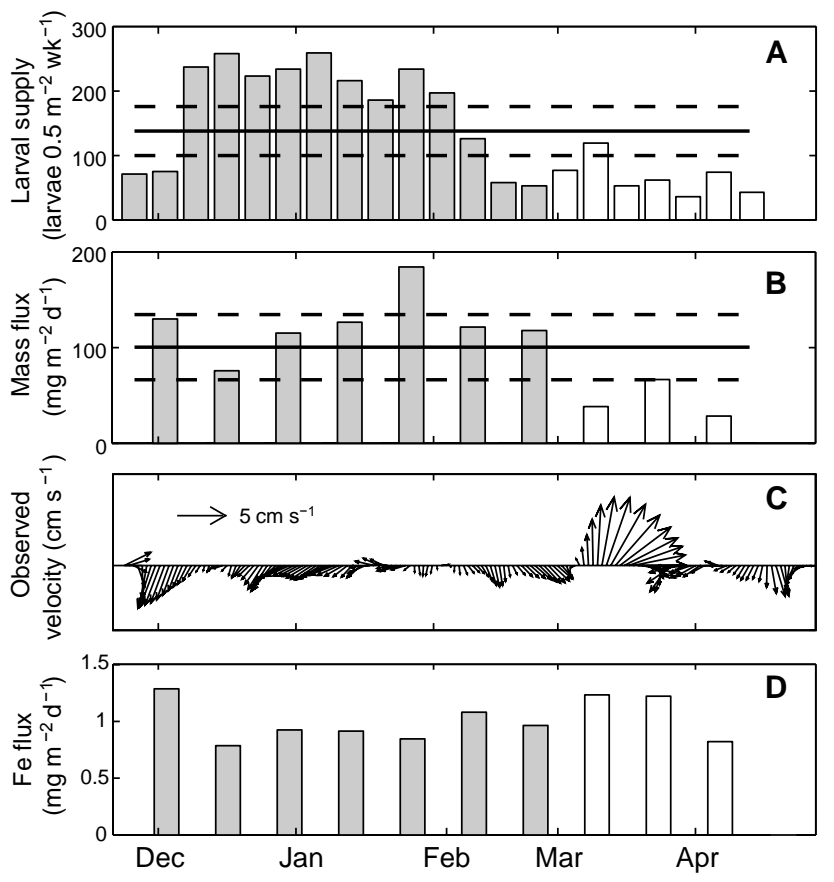

Fig 1 

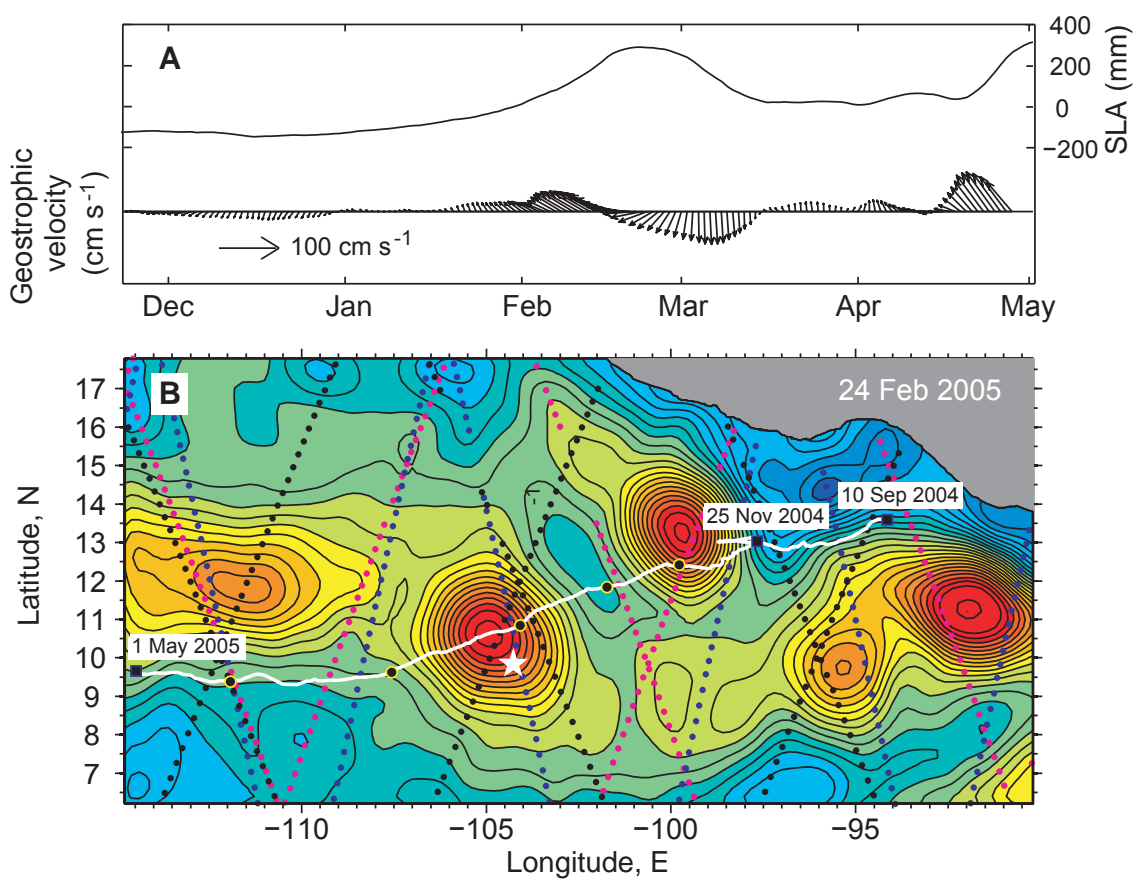

Sea level anomaly (mm)

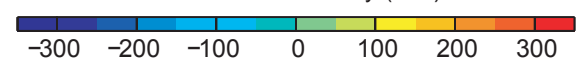

Fig 2 

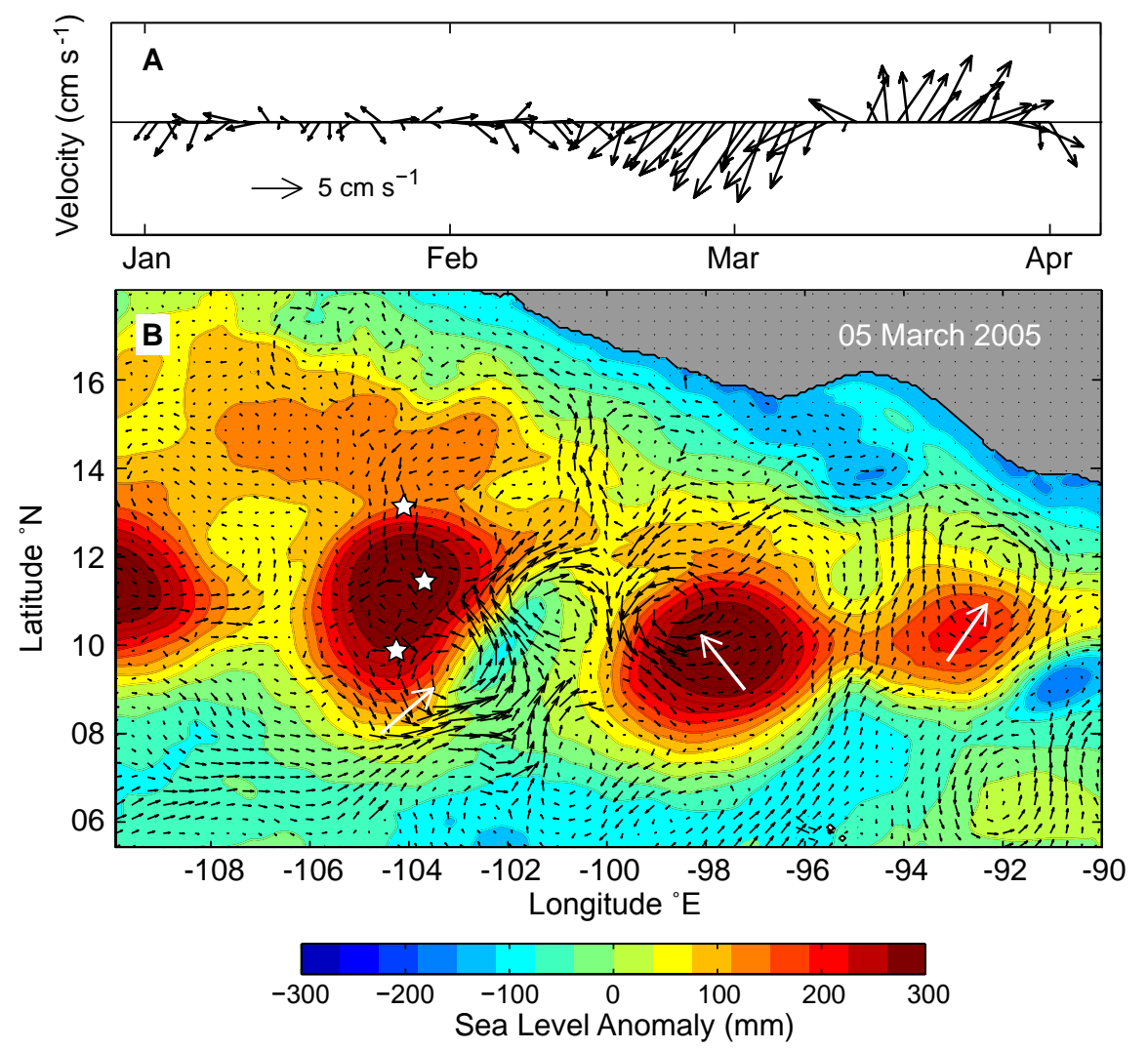

Fig 3 

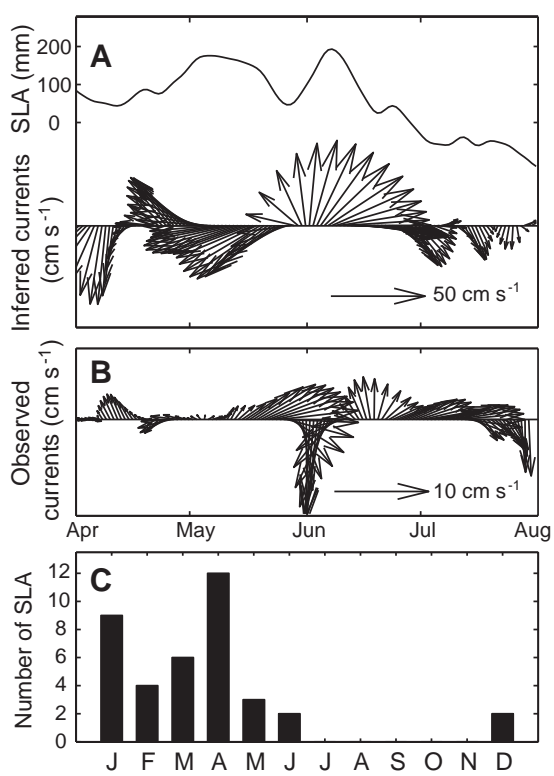

Fig 4 


\section{Supporting Online Material}

Materials and Methods

Supporting Text

Figs. S1, S2, S3, S4, S5, S6

Table S1

SOM References

Legends Movies S1, S2

Movies S1, S2

\section{Materials and Methods}

Time-series larval and geochemical fluxes. Subsurface moorings were positioned within the axial trough within $10 \mathrm{~m}$ of the East Wall $\left(9^{\circ} 50.54^{\prime} \mathrm{N}, 104^{\circ} 17.53^{\prime} \mathrm{W}\right)$ and Choo Choo (9 49.61' $\mathrm{N}, 104^{\circ} 17.37^{\prime} \mathrm{W}$ ) vent sites (S1, S2). Each mooring was equipped with a McLane PARFLUX Mark 78H-21 time-series sediment trap at 4 meters above bottom (mab) with a 0.5

$\mathrm{m}^{2}$ opening, sampling settling particles on 7-day intervals between November 25, 2004 and April 21, 2005 (S2). On recovery, we maintained trap samples at approximately $4{ }^{\circ} \mathrm{C}$ until the larvae were sorted and identified morphologically (S3) under a dissecting microscope to the lowest taxonomic level possible (e.g., species level for most gastropods). Only the supply of gastropod larvae assigned as endemic to hydrothermal vents, either due to species-level identification or identification to families endemic to vents, are presented.

We present East Wall larval fluxes in the main body and Choo Choo larval fluxes in supporting online material because corresponding geochemical analyses were only done on East Wall samples. Additionally, larval supply to Choo Choo is more variable because it is relatively isolated from other larval sources (S1).

The residual of every-other East Wall trap sample were split into fine size fractions $(<300$ $\mu \mathrm{m}$ or $<1 \mathrm{~mm})$ and coarse fractions (>300 $\mu \mathrm{m}$ or $>1 \mathrm{~mm}$ ) using nylon sieves. Each fraction was later filtered through $47 \mathrm{~mm}$ filters (Durapore ${ }^{\mathrm{TM}}, 0.45 \mu \mathrm{m}$ Cat. No. HVLP04700), dried under class-100 laminar flow hood, and weighed to determine mass flux. 
Filtered samples were dissolved to determine elemental composition by inductively coupled plasma mass spectrometry (ICP-MS) at the Woods Hole Oceanographic Institution. The filters were leached overnight with $10 \mathrm{ml}$ of $8 \mathrm{~N}$ distilled $\mathrm{HNO}_{3}$ in $15 \mathrm{ml}$ closed Teflon vials on a hot plate at $80^{\circ} \mathrm{C}$. The solutions were then slowly evaporated to dryness. A second dissolution step using $0.5 \mathrm{ml}$ of concentrated ultrapure $\mathrm{HF}$ and $3 \mathrm{ml}$ of concentrated distilled $\mathrm{HNO}_{3}$ was then used to obtain a total digestion of the particles. The solid residue was dissolved in $10 \mathrm{ml}$ of $2 \%$ $\mathrm{HNO}_{3}$ (Optima grade) and an aliquot was further diluted for multi-elemental ICP-MS analyses. Multi-elemental analysis of the digests was carried out on an ICP-MS Thermo-Electron Element 2 after appropriate dilution (typically 25- to 200-fold dilution depending the amount of digested materials). The detection limit of approximately $0.01 \mathrm{wt} \%$ for $\mathrm{Fe}, \mathrm{Al}, \mathrm{Zn}$ and $0.001 \mathrm{wt} \%$ for $\mathrm{Mn}$, $\mathrm{Cu}$, and $\mathrm{P}$ was calculated from repeat analysis of blank filter digests. Indium was added to each sample as an internal standard to correct for changes of instrument sensitivity. Stock $1000 \mu \mathrm{g} \mathrm{L}^{-1}$ standards (Specpure, Spex) of each element of interest were diluted in preparation for instrument calibration (ranging from 5 to $1000 \mathrm{ppb}$ ). A number of geo-reference standards (BHVO-1 and IFG) were also analyzed along with the samples to confirm analytical accuracy with is better than $5 \%$ for all element reported.

Near-bottom current velocities. Concurrent with the five months of larval and geochemical collections, each of the on-axis moorings (above) and a third mooring positioned 2 kilometers off-axis from East Wall, 9 50.36’ N, 104 18.57’ W, were equipped with Aanderaa current meters at $170 \mathrm{mab}$ (on-axis) and 10 mab (off-axis). Currents were measured using Aanderaa RCM11 current meters recording every 30 min (East Wall and off-axis) or an Aanderaa RCM8 current meter recording every 10 min (Choo Choo). From May to July 2007, currents were measured using an Aanderraa RCM11 current meter at $9^{\circ} 50.0^{\prime} \mathrm{N}, 104^{\circ} 17.4^{\prime} \mathrm{W}$, at $2430 \mathrm{~m}$ depth (70 mab), recording every 20 minutes. Mesoscale variations were assessed using low-pass filtered $(150 \mathrm{~h})$ current records to remove tidal and inertial frequencies. The high-frequency 
residuals were also analyzed for weekly variability. All cross-correlations among observed, simulated and inferred current velocities were done in Matlab v.7.

Statistical analyses. We used permutation tests to determine whether the larval, mass and geochemical fluxes were significantly lower during and after (post) the velocity anomaly than expected by chance alone. The data were randomized 50,000 times and resampled to generate a density curve from which the likelihood of obtaining the observed post-anomaly mean was determined. We used the beginning of the anomalous northward currents, estimated to be March 03, 2005, as the a priori break point between pre- and post-anomaly.

Satellite observations. We performed daily objective analysis (OA) using satellite observations of sea level anomalies from Jason, Topex/Poseidon 2, ENVIronmental SATellite (Envisat), and GEOSAT Follow-On (GFO) produced by AVISO (S4) to detect mesoscale eddies in the region. We used a modified form of the correlation function proposed in by Siegel and colleagues (S5) in which the phase speed was set to zero $(c 1=180 \mathrm{~km}, \mathrm{c} 2=600 \mathrm{~km}, \mathrm{c} 3=20 \mathrm{~d}$ and $\mathrm{c} 4=0)$. Since the satellite track coverage is dense, tracking the inferred eddies gives phase speeds similar to those in the literature. Sea level anomalies are presented as residuals after removal of the long term mean, including mean circulation and the geoid.

The months when anticyclones crossed the East Pacific Rise was tabulated based on published weekly objective analysis from 1993-2004 (S6) and daily objective analysis performed as above from 2004-2009.

HYCOM Modelling. HYCOM is the HYbrid vertical Coordinate Ocean Model, which is isopycnal in the open stratified ocean, terrain-following in shallow coastal regions, and z-level in mixed layer and unstratified regions. This generalized vertical coordinate approach is dynamic in space and time via the layered continuity equation that allows a smooth dynamical transition between the coordinate types. The HYCOM version used in this study is characterized by $1 / 12^{\circ}$ horizontal grid resolution ( $\sim 7 \mathrm{~km}$ at mid-latitude), 32 vertical hybrid layers, and it extends from 
$74^{\circ} \mathrm{S}$ to $90^{\circ} \mathrm{N}$. It is forced with three-hourly winds and daily averaged heat fluxes from the Fleet Numerical Meteorology and Oceanography Center’s Navy Operational Global Atmospheric Prediction System (NOGAPS) (S7), and it includes monthly rivers and turbidity forcing (S8). It integrates during the period January 2003 - June 2006. The model includes realistic bottom topography and coastline geometry that are based on a modified version of the $1 / 30^{\circ} \mathrm{NRL}$ DBDB2 topography (S9). The model uses the 5 meter isobath as a land-sea boundary, and does not include ocean data assimilation. Simulated current velocities were extracted from the approximate location of East Wall, 9 $9^{\circ} 50.5^{\prime} \mathrm{N}, 104^{\circ} 17.5^{\prime} \mathrm{W}$ at $2350 \mathrm{~m}$ depth and near surface for the first ninety days of 2005. 


\section{Supporting Text - Geochemical Analyses}

Mass fluxes collected in sediment traps deployed near hydrothermal fields record integrated particulate fall-out from multiple sources, including lithogenic inputs from hydrothermal, volcanic, and continental sources, and biogenic inputs from hydrothermal and pelagic sources. Significant contributions of lithogenic volcanic or continental debris would result in a Hydrothermal Index (S10), $100 \times[\mathrm{Al}] /([\mathrm{Al}]+[\mathrm{Fe}]+[\mathrm{Mn}])$, above 40 due to their relatively high Al content. Since all Hydrothermal Index values remain below 32 (lower values indicate higher hydrothermal contribution; Table S1) throughout the time series, all samples have a strong hydrothermal component to their lithogenic content, as opposed to a volcanic or detrial component.

However, the hydrothermal lithogenic component, resulting from mineral particulates settling from the overlying plume supplied by high-temperature 'black smoker' venting, cannot account for the drop in mass flux observed at the end of the time series (Fig 1B). Mineral fallout from the plume is high in $\mathrm{Fe}, \mathrm{Cu}$ and $\mathrm{Zn}$, which all remain relatively constant throughout the time series (Fig 1D, Table S1), suggesting that hydrothermal input from high-temperature venting did not change significantly. Consistent with a steady lithogenic hydrothermal input, P:Fe mass ratios (Table S1) fell below 0.10, which is expected when neutrally-buoyant plume particulates that include both Fe-oxyhydroxides ( $\mathrm{P}: \mathrm{Fe} \sim 0.10$ ) and polymetallic sulfides (P:Fe 0) dominate the flux (S11), only when total mass fluxes decreased late in the time series. Furthermore, the consistency of the lithogenic hydrothermal fluxes implies that they could not have exceeded the minimum mass flux $\left(28 \mathrm{mg} \mathrm{m}^{-2} \mathrm{~d}^{-1}\right)$ which is too small to resolve the observed decrease in mass flux. Significantly higher P fluxes $(\mathrm{p}=0.041$; Table S1) and P:Fe ratios ( $\mathrm{p}=$ 0.025) observed pre-anomaly require that a different source that is P-rich and relatively Fe-poor account for the changes in total mass flux (Fig 1B). 
With negligible continental and volcanogenic contributions and a small, constant hydrothermal lithogenic flux, as discussed above, the change in mass flux was likely due to variation of a biogenic input. Biological fluxes would also be consistent with the observed variation in P. While we can't rule out variation in biogenic input from pelagic production, estimates of pelagic fluxes at other vents, $5-50 \mathrm{mg} \mathrm{m}^{-2} \mathrm{~d}^{-1}$ (S12-14) always accounted for less than $25 \%$ of the corresponding near-vent total mass flux $(S 12, S 13)$ - again, too low to resolve the change in mass flux observed here. Given the close proximity to communities with high levels of chemosynthetic production, we propose that our observations are most consistent with high biogenic flux from adjacent vent communities occurring pre-anomaly that was displaced and slow to re-establish post-anomaly. 


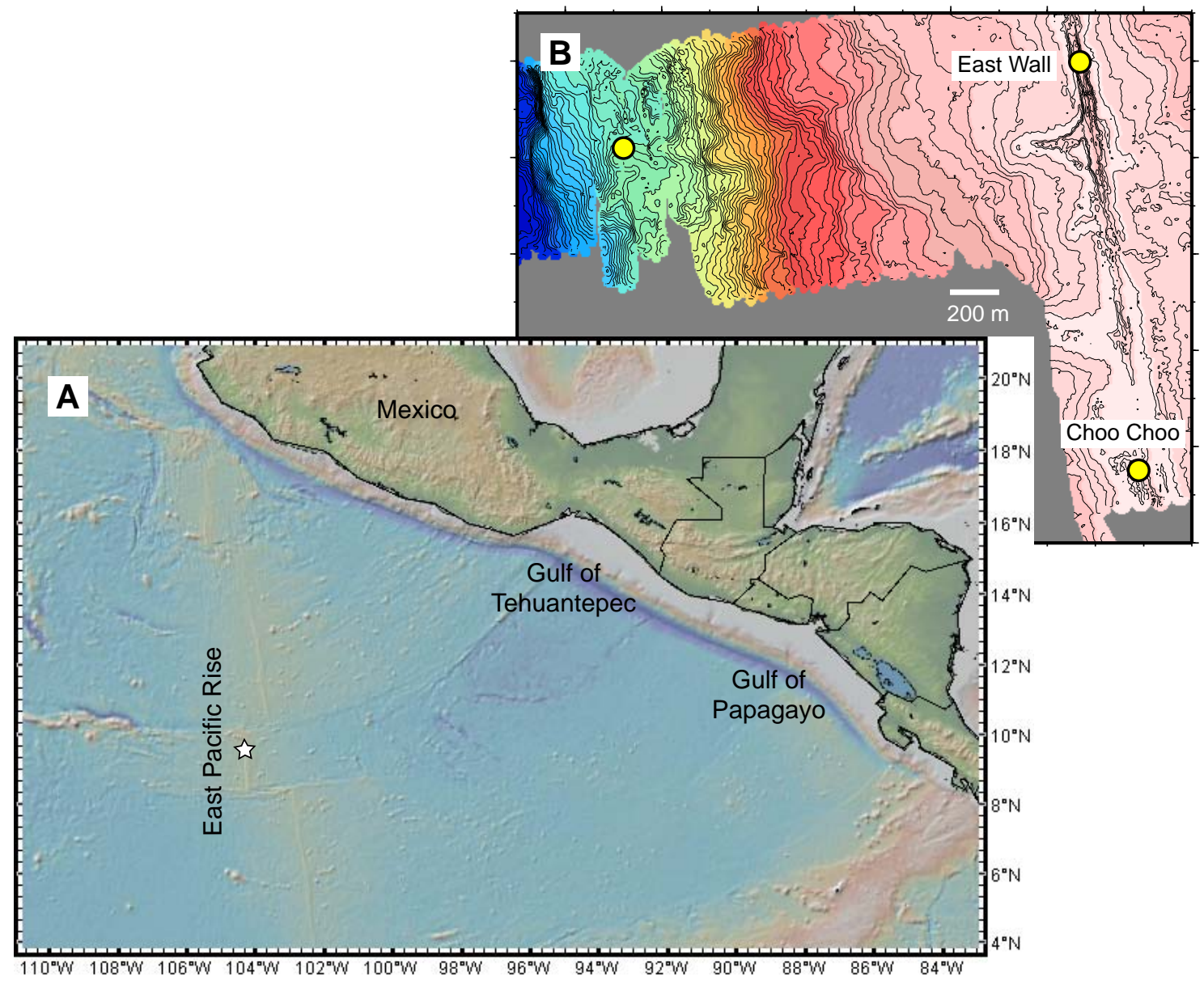

Figure S1. Regional and ridge crest maps of the East Pacific Rise. (A) Regional map showing the topography of Central America and the bathymetry of the East Pacific. The star marks the location of the study site, $9^{\circ} \mathrm{N}$ vent field. Mesoscale eddies impacting the East Pacific Rise are primarily generated in the Gulfs of Tehuantepec and Papagayo. Map created in GeoMapApp. (B) High resolution bathymetry at part of the $9^{\circ} \mathrm{N}$ vent field (red star in A) showing the near-vent study sites at East Wall and Choo Choo and the off-axis study site (circles). Depth contours, $2 \mathrm{~m}$. Tick marks and scale bar, $200 \mathrm{~m}$. 


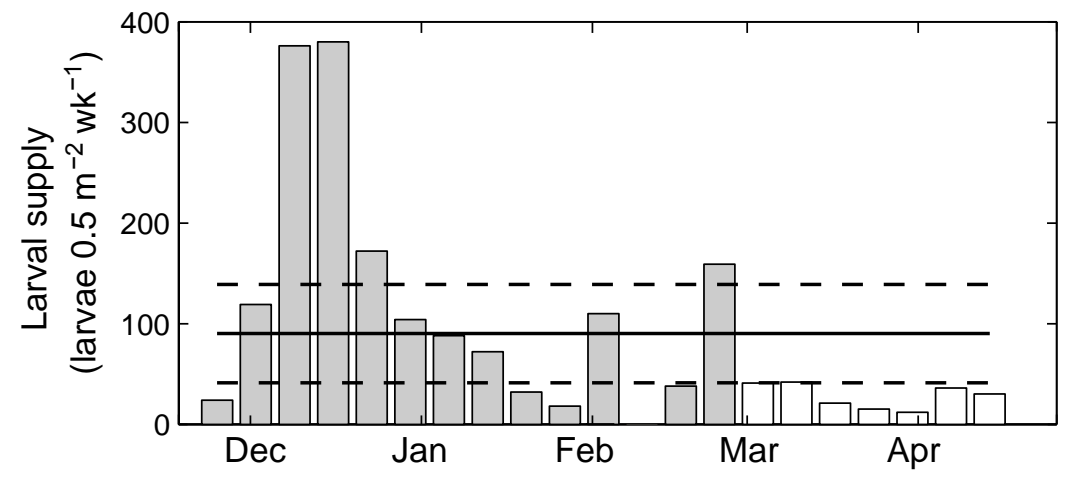

Fig. S2 Supply of vent gastropod larvae to the Choo Choo vent site. Solid line indicates the mean flux. Dashed lines indicate the $95 \% \mathrm{Cl}$. Grey bars indicate samples before (pre-) the current anomaly. Open bars indicate samples during or after the current anomaly (post). Larval supply is generally more variable and lower at Choo Choo compared to East Wall because it is a relatively isolated vent site with fewer local sources (S1). Still, larval supply to Choo Choo post-anomaly was significantly lower than expected ( $p=0.0055$, one-sided permutation test using 50,000 randomizations). 

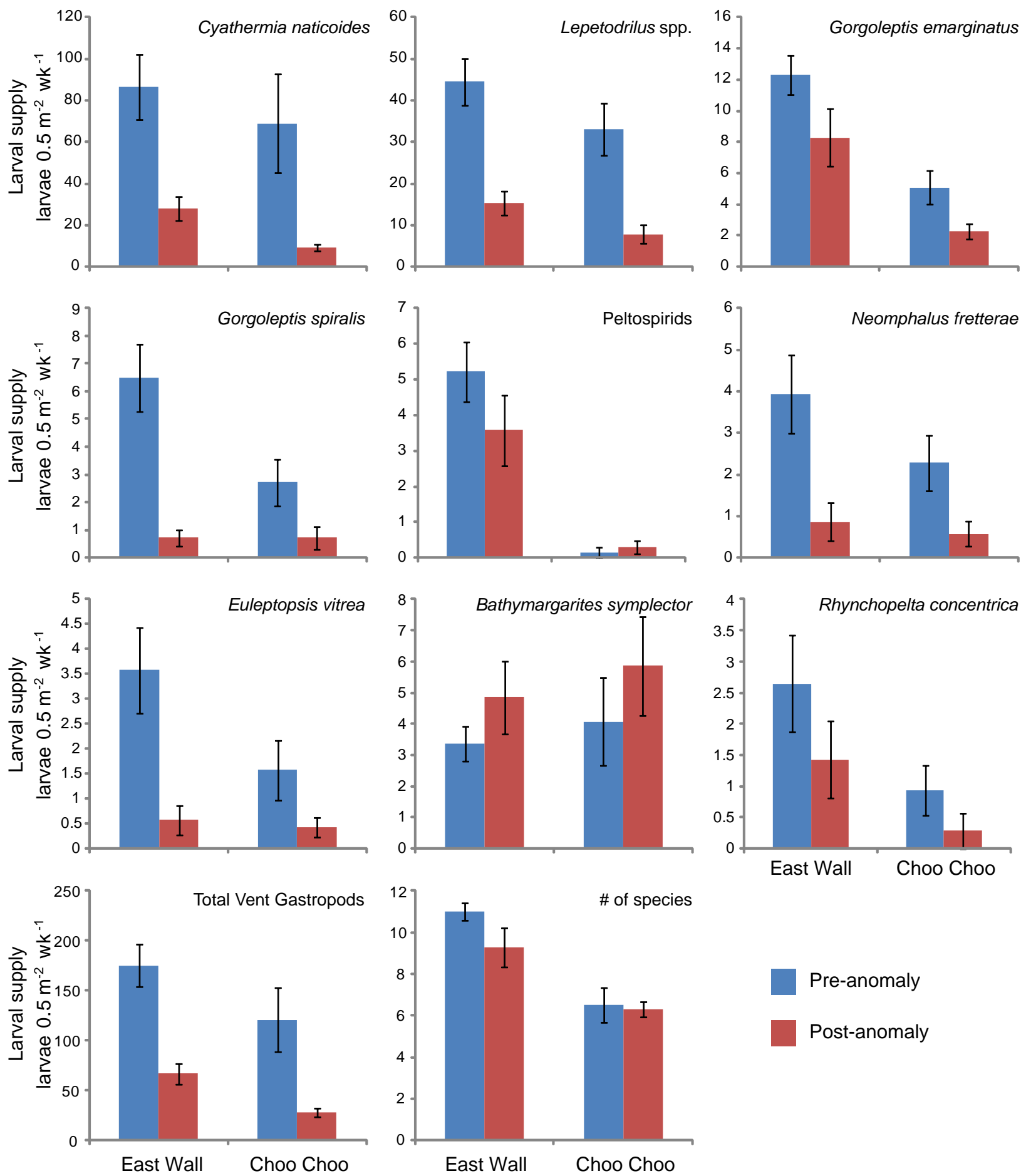

Pre-anomaly

Post-anomaly

Figure S3. Species specific supply pre- and post-anomaly. Larval supply of selected vent gastropod species (with a mean flux greater than 2 per $0.5 \mathrm{~m}^{2}$ per week), total vent gastropods, and the number of species collected before the anomaly (blue) and during and after (post) the anomaly (red) presented as the mean \pm S.E.M. The individual species typically decrease in supply post-anomaly, with the notable exception of Bathymargarites symplector. B. symplector differs from the others in its large size $(320-350 \mu \mathrm{m})(\mathrm{S} 3)$ and ability to feed during its larval stage. It may have enhanced swimming or behavioral capabilities relative to the other species. 


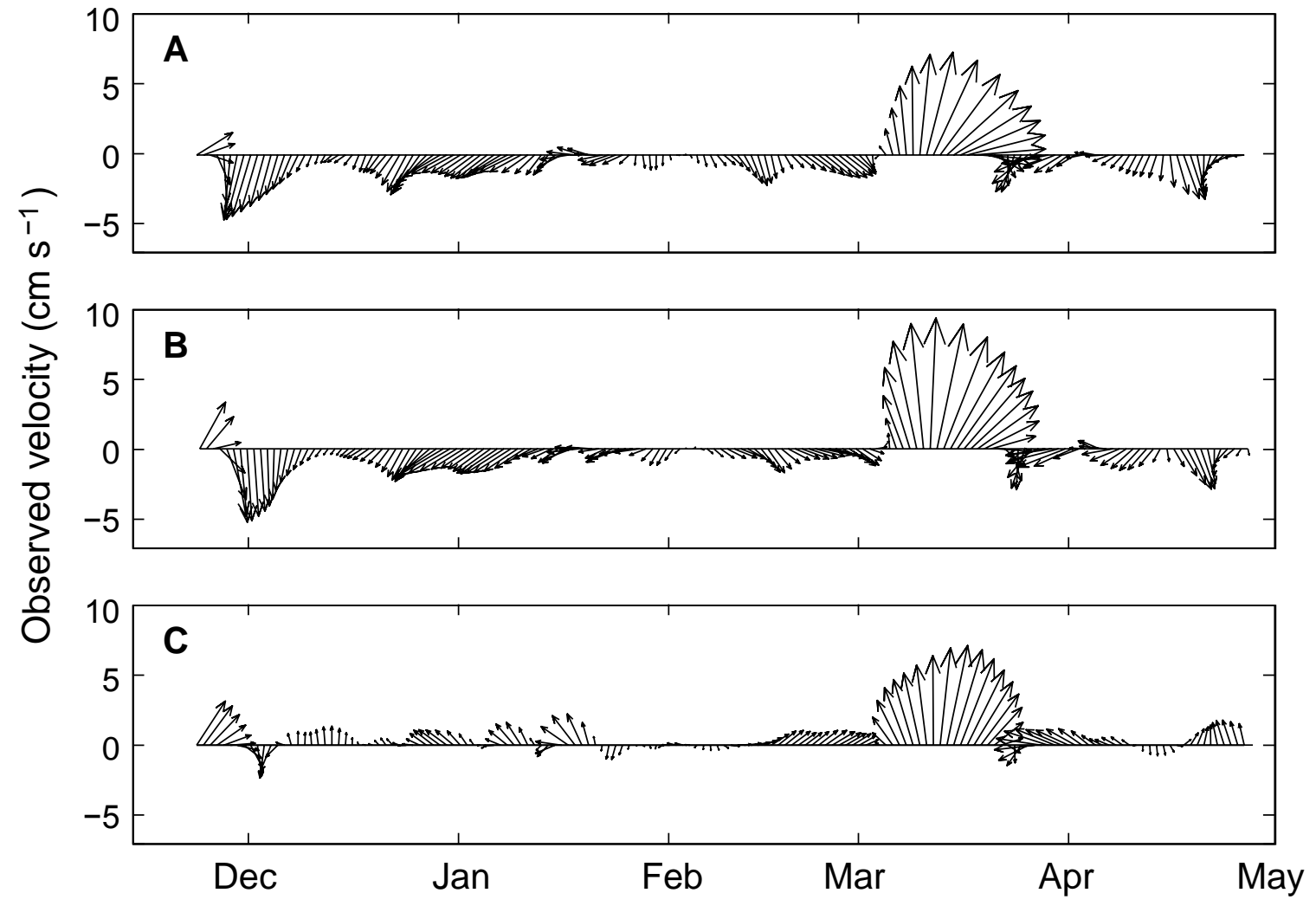

Fig. S4 Current velocities at (A) East Wall vent site at 170 mab, (B) Choo Choo vent site at 170 mab and (C) $2 \mathrm{~km}$ off-axis at 10 mab all show anomalously high current speeds in March with coincident, rapid changes in direction from late February to early April. 


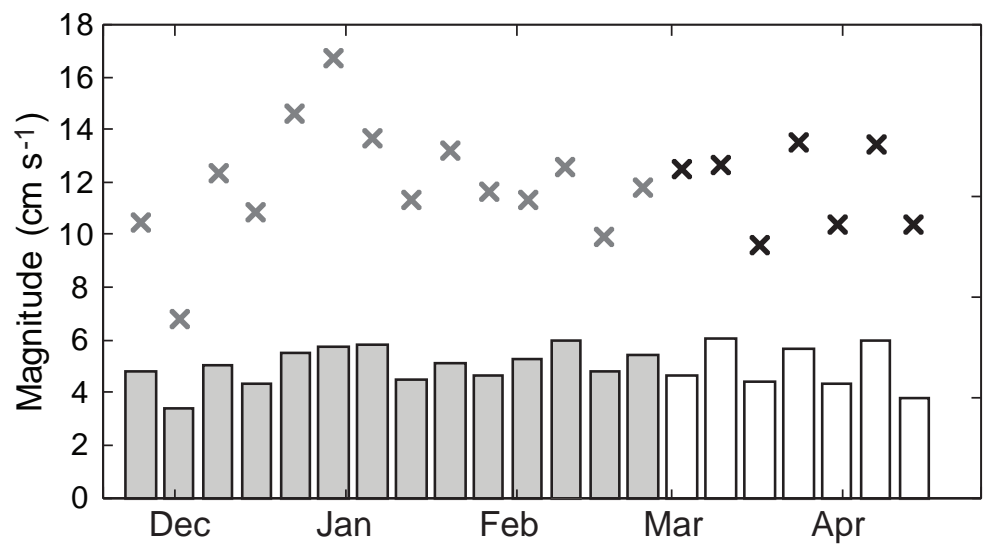

Figure S5. High frequency motions. Root mean square (bars) and maxima (symbols) of the residual high frequency motions in the in the 2004-2005 current meter record from East Wall, $9^{\circ} \mathrm{N}$ EPR. Residuals were computed by subtracting the low frequency motions (Fig. 1C) from the raw data. Grey bars and symbols indicate samples analyzed as before (pre) the current anomaly. Open bars and black symbols indicate samples during or after (post) the current anomaly. The weekly rms and maxima were not significantly lower than expected post-anomaly ( $p=0.441$ and $p=0.437$, respectively, one sided permutation test using 50,000 randomizations). 

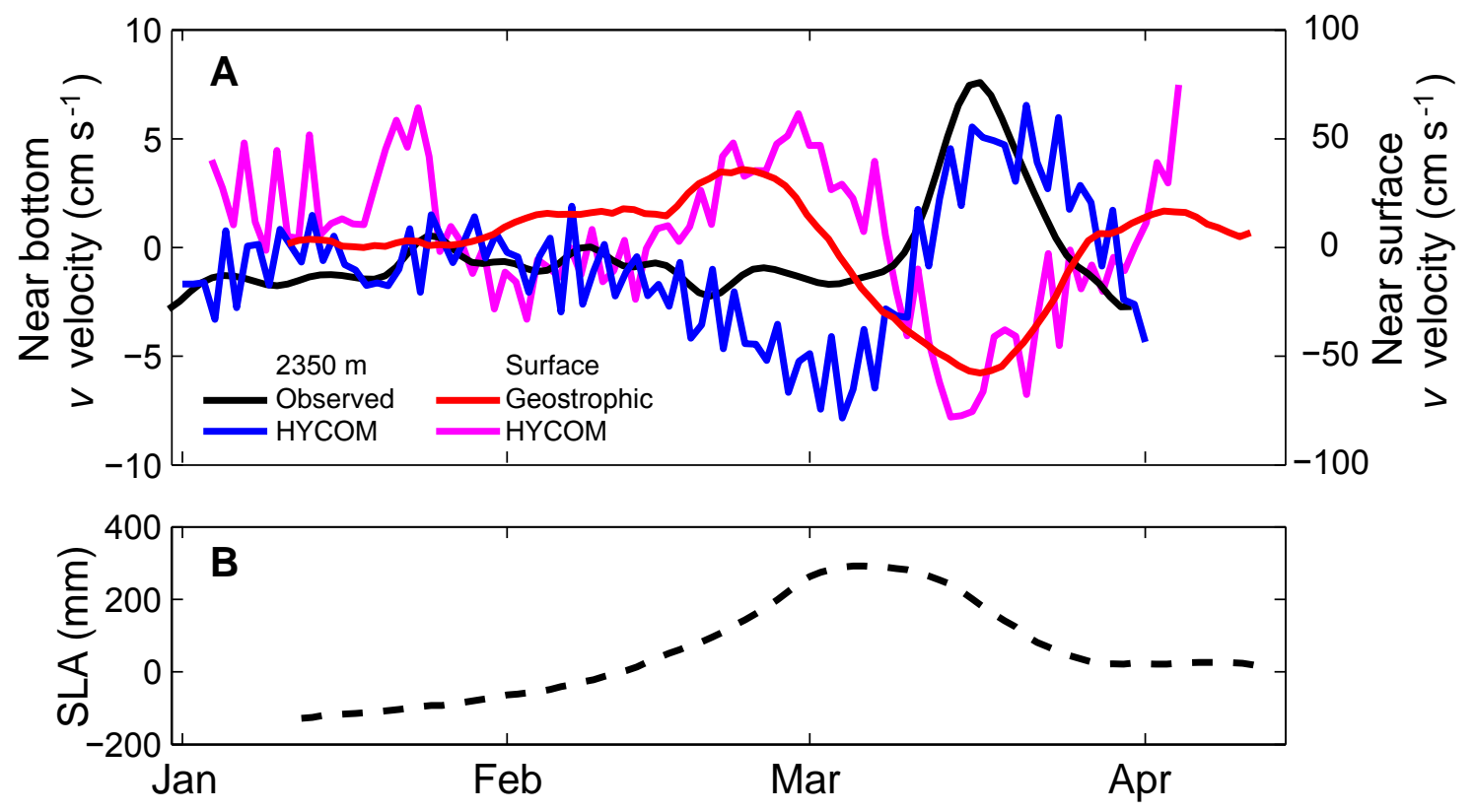

Fig. S6 (A) Comparison of the meridional component of the observed current velocities at East Wall, $2350 \mathrm{~m}$ depth (black), the inferred geostrophic current velocities (red), and simulated HYCOM current velocities at $2350 \mathrm{~m}$ depth (blue) and near the surface (magenta) for the first 90 days of 2005. Geostrophic velocities and HYCOM surface velocities are plotted shifted 8 days and 5 days later, respectively. (B) Corresponding sea level anomaly, plotted with an 8 day shift. 
Supplementary Table 1. Geochemical fluxes at East Wall.

\begin{tabular}{|c|c|c|c|c|c|c|c|c|c|c|c|}
\hline Cup Number & 2 & 4 & 6 & 8 & 10 & 12 & 14 & 16 & 18 & 20 & \\
\hline Start Date & 2-Dec-04 & 16-Dec-04 & 30-Dec-04 & 13-Jan-05 & 27-Jan-05 & 10-Feb-05 & 24-Feb-05 & 10-Mar-05 & 24-Mar-05 & 7-Apr-05 & \\
\hline End Date & 9-Dec-04 & 23-Dec-04 & 6-Jan-05 & 20-Jan-05 & 3-Feb-05 & 17-Feb-05 & 3-Mar-05 & 17-Mar-05 & 31-Mar-05 & 14-Apr-05 & $\mathrm{p}$ value \\
\hline $\begin{array}{l}\text { Mass Flux } \\
\left(\mathrm{mg} \mathrm{m}^{-2} \mathrm{~d}^{-1}\right)\end{array}$ & 130 & 76 & 115 & 126 & 184 & 121 & 118 & 38 & 67 & 28 & 0.008 \\
\hline $\begin{array}{l}\text { Fe flux } \\
\left(\mathrm{mg} \mathrm{m}^{-2} \mathrm{~d}^{-1}\right)\end{array}$ & 1.29 & 0.79 & 0.93 & 0.92 & 0.85 & 1.08 & 0.96 & 1.23 & 1.22 & 0.82 & 0.206 \\
\hline $\begin{array}{l}\text { Al flux } \\
\left(\mathrm{mg} \mathrm{m}^{-2} \mathrm{~d}^{-1}\right)\end{array}$ & 0.66 & 0.39 & 0.46 & 0.47 & 0.40 & 0.46 & 0.46 & 0.28 & 0.56 & 0.34 & 0.143 \\
\hline $\begin{array}{l}\text { Mn flux } \\
\left(\mathrm{mg} \mathrm{m}^{-2} \mathrm{~d}^{-1}\right)\end{array}$ & 0.15 & 0.11 & 0.11 & 0.13 & 0.10 & 0.15 & 0.14 & 0.10 & 0.21 & 0.08 & 0.440 \\
\hline $\begin{array}{l}\text { Cu flux } \\
\left(\mathrm{mg} \mathrm{m}^{-2} \mathrm{~d}^{-1}\right)\end{array}$ & 0.048 & 0.025 & 0.020 & 0.023 & 0.018 & 0.020 & 0.016 & 0.031 & 0.013 & 0.009 & 0.217 \\
\hline $\begin{array}{l}\text { Zn flux } \\
\left(\mathrm{mg} \mathrm{m}^{-2} \mathrm{~d}^{-1}\right)\end{array}$ & 0.035 & 0.019 & 0.031 & 0.050 & 0.021 & 0.031 & 0.030 & 0.035 & 0.022 & 0.030 & 0.441 \\
\hline $\begin{array}{l}\text { P flux } \\
\left(\mathrm{mg} \mathrm{m}^{-2} \mathrm{~d}^{-1}\right)\end{array}$ & 0.19 & 0.12 & 0.19 & 0.24 & 0.12 & 0.092 & 0.087 & 0.093 & 0.089 & 0.058 & 0.041 \\
\hline $\begin{array}{l}\text { Hydrothermal } \\
\text { Index }\end{array}$ & 32 & 30 & 31 & 31 & 29 & 27 & 29 & 17 & 28 & 27 & 0.025 \\
\hline $\mathrm{P}: \mathrm{Fe}$ & 0.15 & 0.15 & 0.21 & 0.26 & 0.14 & 0.085 & 0.090 & 0.076 & 0.073 & 0.071 & 0.025 \\
\hline
\end{tabular}

Total mass flux and flux of six elements analyzed by ICP-MS for every other sample (cup) in the time-series sediment trap collection. The Hydrothermal Index $\{100 \mathrm{x}[\mathrm{Al}] /([\mathrm{Al}]+[\mathrm{Fe}]+[\mathrm{Mn}])\}$ is a measure of the relative contribution of high-temperature hydrothermal plume fall-out, with lower numbers indicative of a higher contribution to the lithogenic component. Note that the Hydrothermal Index drastically decreases during the current anomaly (cup 16), but primarily due to a decrease in an Al-rich input rather than an increase in Fe-rich hydrothermal input. Variation in total mass flux was decoupled from the Hydrothermal Index because the Hydrothermal Index only reflects changes in the lithogenic contribution which was a small portion of the total mass flux. The p-value for fluxes that were significantly lower than expected post-anomaly compared to pre-anomaly ( $p<0.05, n=10$, permutation test with 50,000 randomizations) are in bold. 


\section{SOM References}

S1. Adams, D. K. \& Mullineaux, L. S. (2008) Supply of gastropod larvae to hydrothermal vents reflects transport from local larval sources. Limnology and Oceanography 53, 1945-1955.

S2. Mullineaux, L. S., Adams, D. K., Mills, S. W. \& Beaulieu, S. E. (2010) Larvae from afar colonize deep-sea hydrothermal vents after a catastrophic eruption. Proceedings of the National Academy of Sciences of the United States of America 107, 7829-7834.

S3. Mills, S. W., Beaulieu, S. E. \& Mullineaux, L. S. in Woods Hole Oceanographic Institution Technical Report WHOI-2009-5 (Woods Hole Oceanographic Institution, Woods Hole, MA, 2009).

S4. Altimeter products were produced by Ssalto/Duacs and distributed by Aviso with support from Cnes; see http://www.aviso.oceanobs.com/

S5. Siegel, D., McGillicuddy, D. \& Fields, E. (1999) Mesoscale eddies, satellite altimetry, and new production in the Sargasso Sea. Journal of Geophysical Research 104, 1335913379.

S6. Palacios, D. M. \& Bograd, S. J. (2005) A census of Tehunatepec and Papagayo eddies in the northeastern tropical Pacific. Geophysical Research Letters 32, doi:10.1029/2005GL024324.

S7. $\quad$ Rosmond, T. E., Teixeira, J., Peng, M., Hogan, T. F. \& Pauley, R. (2002) Navy Operational Global Atmospheric Predictions System (NOGAPS): Forcing for ocean models. Oceanography 15, 99-108.

S8. Kara, A. B., Wallcraft, A. J. \& Hurlburt, H. E. (2005) How does solar attenuation depth affect the ocean mixed layer? Water turbidity and atmospheric forcing impacts on the simulation of seasonal mixed layer variability in the turbid Black Sea. Journal of Climate 18, 389-409.

S9. http://www7320.nrlssc.navy.mil/DBDB2_WWW

S10. Boström, K., Peterson, M. N. A., Joensuu, O. \& Fisher, D. E. (1969) Aluminium-poor ferromaganoan sediments on active oceanic ridges. Journal of Geophysical Research 74, 3261-3270.

S11. Feely, R. A., Trefry, J. H., Lebon, G. T. \& German, C. R. (1998) P/Fe and V/Fe ratios in hydrothermal precipitates: Potential new paleo-proxies for dissolved phosphate in seawater. Geophysical Research Letters 25, 2253-2256.

S12. German, C. R., Colley, S., Khripounoff, A., Klinkhammer, G. P. \& Palmer, M. R. (2002) Hydrothermal sediment trap fluxes: $13^{\circ} \mathrm{N}$, East Pacific Rise. Deep Sea Research I 49, 1921-1940. 
S13. Khripounoff, A. et al. (2008) Temporal variation of currents, particulate flux and organism supply at two deep-sea hydrothermal fields of the Azores Triple Junction. Deep-Sea Research I 55, 532-551.

S14. Cowen, J. P. et al. (2001) Acending and descending particle flux from hydrothermal plumes at Endeavour Segment, Juan de Fuca Ridge. Deep Sea Research I 48, 1093-1120. 


\section{Legends Movies S1, S2}

Movie S1. Daily objective analysis of sea level anomaly in the tropical East Pacific showing an initial period early in the study with little eddy activity followed by the development of predominantly anticyclonic mesoscale eddies during the winter in the Gulfs of Tehuantepec and Papagayo off the coast of Central America. Eddies propagated across the East Pacific Rise (white line) and hydrothermal vent fields (circles) including the study site (star) in mid February through the end of the time series. (mpeg; 6.7 MB; higher resolution movie deposited in Marine Geoscience Data System, http://www.marine-geo.org/portals/ridge2000/)

Movie S2. HYCOM model output showing sea surface height (SSH) anomaly and bottom currents from to 15 Jan (year day 15) to 27 March 2005 (year day 86). Note the relatively weak bottom currents at the beginning of the time series, followed by strong currents in coherent structures as large sea surface height anomalies develop in the latter half of the time series. A deep cyclonic feature developed just to the south of the anticyclone by mid-February. The propagation of this deep cyclone appeared to be impeded by the East Pacific Rise, such that the anticyclone crossed the ridge before the deep cyclone - consistent with the lag between the observed near-bottom velocity anomaly and the inferred geostrophic velocities. The bottom currents associated with the eddy field were complex and included both cyclonic and anticyclonic features and large connecting flows that persisted for weeks. (mpeg; $6 \mathrm{MB}$; higher resolution movie deposited in Marine Geoscience Data System, http://www.marinegeo.org/portals/ridge2000/) 